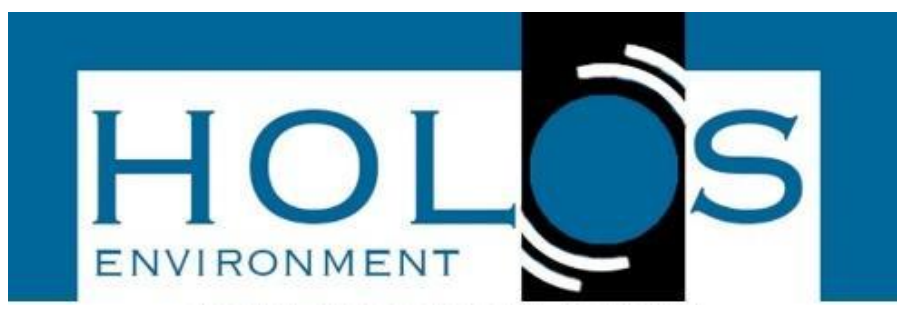

\title{
QUALIDADE DA ÁGUA UTILIZADA PARA CONSUMO HUMANO EM ÁREAS RURAIS, ESTUDO DE CASO NO MUNICÍPIO DE SANTA ROSA DO SUL-SANTA CATARINA
}

\section{QUALITY OF WATER USED FOR HUMAN CONSUMPTION IN RURAL AREAS, A CASE STUDY IN SANTA ROSA DO SUL-SANTA CATARINA/BRAZIL}

\author{
Gustavo Simão"; Ana Paula Martins Damiani²; Nadja Zim Alexandre3; \\ Bruna Gonçalves da Silva ${ }^{4}$
}

Artigo recebido em: 10/01/2020 e aceito para publicação em: 18/01/2020.

DOI: http://dx.doi.org/10.14295/holos.v20i1.12368

Resumo: Água potável e saneamento seguros são reconhecidos como direitos básicos. A água destinada para consumo humano tem sido frequentemente reconhecida como veículo de transmissão de enfermidades. Muitas epidemias tiveram sua origem na distribuição e abastecimento de águas. Aproximadamente $15 \%$ da população brasileira vive na zona rural, são por volta de 29 milhões de pessoas, as quais prioritariamente vivem sem acesso aos serviços de saneamento como água tratada. Segundo dados oriundos da Vigilância Sanitária do Estado de Santa Catarina para a região da AMESC, dos sistemas autônomos de capitação de água (poços, nascentes etc.), 60\% indicaram a presença de Coliformes Totais e $34 \%$ indicaram a presença de E. Coli. Estes números motivaram a realização do presente trabalho. Neste sentido, buscando avaliar a qualidade da água consumida pelas comunidades rurais, como case, selecionaram-se duas comunidades do munícipio de Santa Rosa do Sul, no sul do estado de Santa Catarina, nas quais foram avaliados um conjunto de propriedades 10 propriedades cada, em conformidade com seu contexto hidrogeológico e subsequente forma de captação de água (nascentes e poços ponteira). Mesmo para o diminuto número de parâmetros avaliados, 90\% das amostras obtidas em nascentes não apresentaram condições de potabilidade, predominantemente relacionada a parâmetros microbiológicos. A situação nas captações do tipo ponteira é um pouco melhor, com $30 \%$ das amostras em condição de potabilidade. O maior problema neste contexto está associado à presença de alumínio com concentração acima do limite estabelecido para potabilidade.

Palavras-chave: Água potável. Saúde Pública. Hidrogeologia. Saneamento Básico.

\begin{abstract}
Safe drinking water and sanitation are recognized as basic rights. Water intended for human consumption has often been recognized as a vehicle for disease transmission. Many epidemics originated in water distribution and supply. Approximately $15 \%$ of the Brazilian population lives in rural areas, around 29 million people, who mainly live without access to sanitation services such as treated water. According to data from the Santa Catarina State Sanitary Surveillance for the AMESC region, from the autonomous water capitation systems (wells, springs, etc.), $60 \%$ indicated the presence of Total Coliforms and $34 \%$ indicated the presence of $\mathrm{E}$. Coli. These numbers motivated the accomplishment of the present work. In this sense, seeking to evaluate the quality of water consumed by rural communities,

1 Universidade do Extremo Sul Catarinense (UNESC), Criciúma, SC / Universidade Federal do Rio Grande do Sul (UFRGS). E-mail: (imao.geologia@gmail.com)

2 Empresa de Pesquisa Agropecuária e Extensão Rural de Santa Catarina (EPAGRI). E-mail: (anadamiani@epagri.sc.gov.br)

3 Instituto de Meio Ambiente do Estado de Santa Catarina (IMA). E-mail: (nadjaalexandre@ima.sc.gov.br)

4 Universidade do Extremo Sul Catarinense (UNESC), Criciúma. E-mail: (brunasilvaamb@hotmail.com)
\end{abstract}


as case, we selected two communities of Santa Rosa do Sul, in the south of Santa Catarina state, in which a set of properties were evaluated 10 properties each, in accordance with its hydrogeological context and subsequent form of water abstraction (springs and wells tip). Even for the small number of parameters evaluated, $90 \%$ of the samples obtained in springs did not present potability conditions, predominantly related to microbiological parameters. The situation in tip-type uptake is slightly better, with $30 \%$ of the samples in potable condition. The biggest problem in this context is associated with the presence of aluminum with concentration above the limit established for potability.

Keywords: Potable water. Public health. Hydrogeology. Basic sanitation.

\section{INTRODUÇÃO}

Água potável e saneamento seguros são reconhecidos como direitos básicos, uma vez que eles são indispensáveis para sustentar meios de subsistência saudáveis e fundamentais para manter a dignidade de todos os seres humanos (UNESCO, 2019). Em termos mundiais, a oferta de água tem relação intrínseca com a segurança alimentar, o estilo de vida das pessoas, o crescimento industrial e agrícola e a sustentabilidade ambiental (BERNARDI, 2003).

Segundo UNESCO (2019), a nível mundial, três entre cada dez pessoas não têm acesso a água potável segura. Seis entre cada dez pessoas não têm acesso a serviços de saneamento gerenciados de forma segura. A disponibilidade hídrica depende da quantidade de água fisicamente disponível, e da forma como ela é armazenada, administrada e alocada para vários usuários. Ela inclui aspectos relacionados à gestão das águas superficiais e subterrâneas, assim como à reciclagem e ao reuso da água.

Segundo a Organização Mundial da Saúde (WHO, 2011), na maioria dos países, há populações cuja água é derivada de fontes domésticas, como poços privados e águas pluviais. O maior risco para a saúde pública causado por microrganismos na água está associado ao consumo de água que é contaminada com excrementos humanos e animais, embora outras fontes e rotas de exposição possam também ser significativas.

A água destinada para consumo humano tem sido frequentemente reconhecida como veículo de transmissão de enfermidades (BRASIL, 2006). Muitas epidemias tiveram sua origem na distribuição e abastecimento de águas, e por este motivo, devese ter uma maior atenção quando o assunto é qualidade. Aágua quando destinada para consumo humano, precisa atender ao padrão de potabilidade estabelecido pela portaria do Ministério da Saúde e não oferecer riscos à saúde (BRASIL, 2017). 
Além da contaminação de origem fecal, outras podem ser as fontes de contaminação, como uso agrícola e industrial, assim como a presença de elementos disponibilizados para a água devido a características geológicas inerentes ao local. Neste sentido podem ser encontrados em maior quantidade nas águas elementos como alumínio, ferro, flúor, manganês e sílica (FEITOSA et. al., 2008).

No meio rural, as principais fontes de abastecimento de água são os poços rasos e as nascentes, fontes estas bastante susceptíveis a contaminação. Como exemplo, no Reino Unido, avaliando-se amostras de água de fontes privadas, identificou-se que $100 \%$ das amostras de poços rasos e $63 \%$ das amostras de nascentes estavam comprometidas quanto a potabilidade (AMARAL et al., 2003 apud FEWTRELL et al, 1998).

Segundo dados do último Censo (IBGE, 2010), aproximadamente $15 \%$ da população brasileira vivia na zona rural. São mais de 8,1 milhões de domicílios, abrigando por volta de 29 milhões de pessoas, as quais prioritariamente vivem sem acesso aos serviços de saneamento como água tratada, destinação adequado dos esgotos e resíduos sólidos, sem controle de vetores e com dificuldades no manejo da água pluvial. Em termos percentuais, o estado de Santa Catarina mantém-se dentro do perfil nacional, com pouco mais de $16 \%$ de sua população residindo em áreas rurais, o que totaliza mais de 1 milhão de pessoas (IBGE, 2010).

Conforme dados do Censo demográfico (IBGE, 2010), o maior déficit em termos de saneamento nas áreas rurais ocorre no esgotamento sanitário, onde $54,2 \%$ dos domicílios possuem atendimento precário e $28,6 \%$ são considerados sem atendimento. Em seguida, encontra-se a gestão dos resíduos sólidos, onde quase $70 \%$ das residências não são atendidas. Este panorama de gestão aponta para um cenário de elevado risco para a saúde pública causada por microrganismos na água, o qual está associado ao consumo de água contaminada com excrementos humanos e resíduos.

No Brasil, os padrões de potabilidade da água são regidos pelo do Ministério da Saúde, através da Portaria de Consolidação $n^{\circ} 5$ de 03 de outubro de 2017. Nela estão descritas as concentrações máximas de substâncias aceitáveis para a destinação ao consumo humano. No capítulo II, art. $5^{\circ}$ desta portaria fica estabelecido que a água potável deve atender ao padrão de potabilidade estabelecido na mesma, o qual não ofereça nenhum tipo de risco à saúde (BRASIL, 2017). 
Esta portaria estabelece que a água potável deve estar em conformidade com padrão microbiológico, ou seja, deve apresentar ausência dos parâmetros microbiológicos em sua constituição, conforme disposto no Anexo 1 do Anexo XX (Quadro 1).

\begin{tabular}{|c|c|c|c|c|}
\hline \multicolumn{2}{|c|}{ Tipo de água } & \multicolumn{2}{|r|}{ Parâmetro } & VMP(1) \\
\hline \multicolumn{2}{|c|}{$\begin{array}{l}\text { Água para consumo } \\
\text { humano }\end{array}$} & \multicolumn{2}{|c|}{ Escherichia coli(2) } & Ausência em $100 \mathrm{~mL}$ \\
\hline \multirow{4}{*}{$\begin{array}{l}\text { Água } \\
\text { tratada }\end{array}$} & $\begin{array}{l}\text { Na saida do } \\
\text { tratamento }\end{array}$ & & liformes totais (3) & Ausência em $100 \mathrm{~mL}$ \\
\hline & \multirow{3}{*}{$\begin{array}{l}\text { No sistema de } \\
\text { distribuição } \\
\text { (reservatórios e } \\
\text { rede) }\end{array}$} & & Escherichia coli & Ausência em 100 mL \\
\hline & & \multirow{2}{*}{ Coliformes totais (4) } & $\begin{array}{l}\text { Sistemas ou soluções alternativas } \\
\text { coletivas que abastecem menos de } \\
20.000 \text { habitantes }\end{array}$ & $\begin{array}{l}\text { Apenas uma amostra, entre as } \\
\text { amostras examinadas no mês, poderá } \\
\text { apresentar resultado positivo }\end{array}$ \\
\hline & & & $\begin{array}{l}\text { Sistemas ou soluções alternativas } \\
\text { coletivas que abastecem a partir } \\
\text { de } 20.000 \text { habitantes }\end{array}$ & $\begin{array}{l}\text { Ausência em } 100 \mathrm{~mL} \text { em } 95 \% \text { das } \\
\text { amostras examinadas no mês. }\end{array}$ \\
\hline
\end{tabular}

Com relação a presença de metais, esta mesma portaria preconiza em termos de potabilidade, concentrações máximas permitidas de $0,2 \mathrm{mg} / \mathrm{L}$ para o metal alumínio e $0,3 \mathrm{mg} / \mathrm{L}$ para o metal ferro. Da mesma forma, a portaria consolidada recomenda $\mathrm{pH}$ numa faixa entre 6,0 a 9,5 .

Tomando-se como exemplo os municípios de compõem a Associação dos Municípios do Extremo Sul Catarinense (AMESC), a qual é composta por 15 municípios que totalizam uma população de aproximadamente 180 mil pessoas, 55 mil das quais residindo em áreas rurais, os números alertam para a gravidade da problemática associada à qualidade de vida das populações rurais (IBGE, 2010).

Segundo dados perfazendo mais de 4 anos de monitoramento (2015-2018), totalizando mais de 4 mil análises oriundas dos boletins de qualidade de água das coletas realizadas pela Vigilância Sanitária do Estado de Santa Catarina (SANTA CATARINA, 2019) para esta região, dos sistemas autônomos de capitação de água (poços, nascentes etc.), 60\% indicaram a presença de Coliformes Totais e $34 \%$ indicaram a presença de E. Coli nas análises (Figura 1). 
Figura 1 - Síntese dos dados microbiológicos da Vigilância Sanitária do Estado de Santa Catarina para a região da AMESC

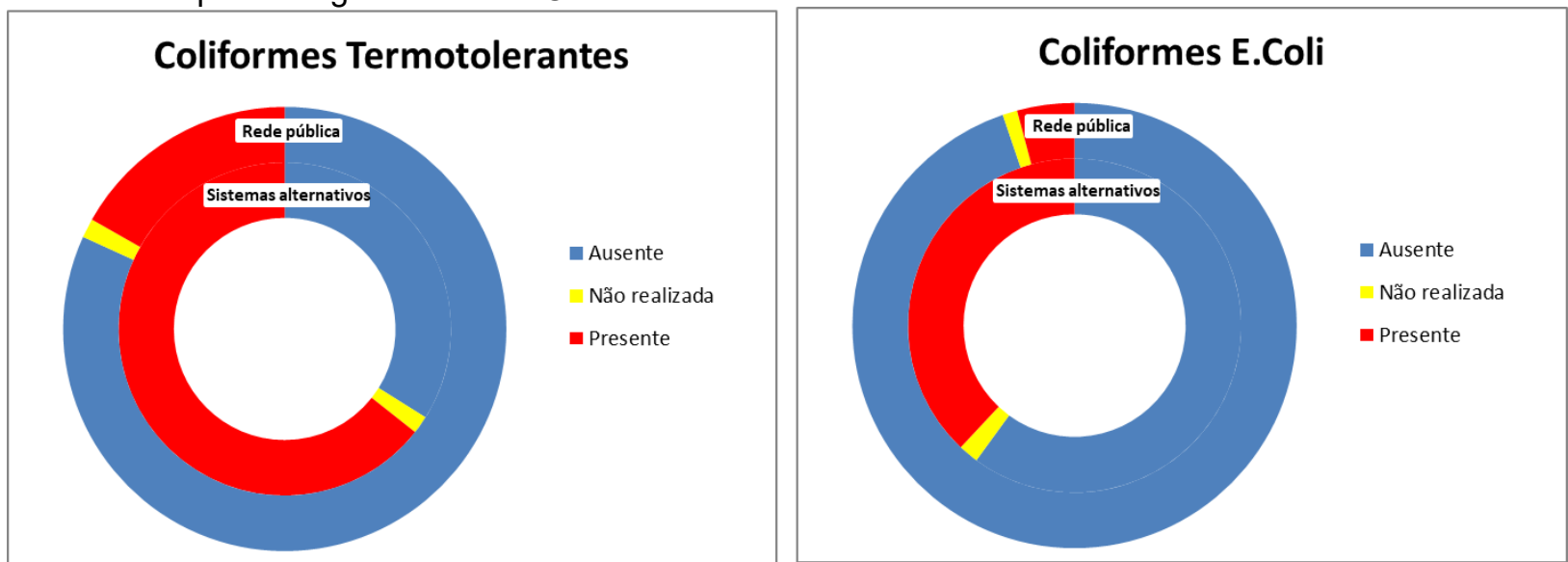

Fonte: Vigilância Sanitária do Estado de Santa Catarina

Estes números motivaram a realização do presente trabalho, o qual vislumbra avaliar por meio de uma abordagem contextual a condição da qualidade da água para consumo humano em área rural no município de Santa Rosa do Sul, baseado nos dados obtidos por Damiani (2017). Este município encontra-se inserido na microrregião da AMESC (Figura 1) e segundo o último Censo (IBGE, 2010), aproximadamente 3.746 pessoas vivem em zona rural sendo que sua população é de 8.054 habitantes. Dessas pessoas, mais de $50 \%$ não tem um sistema de saneamento adequado segundo IBGE (2010). Neste sentido, buscando avaliar a qualidade da água consumida pelas comunidades rurais no município, selecionaram-se duas comunidades nas quais foram avaliados um conjunto de propriedades 10 propriedades cada (Figura 3). 
Figura 2 - Localização dos municípios que compõem a região da AMESC
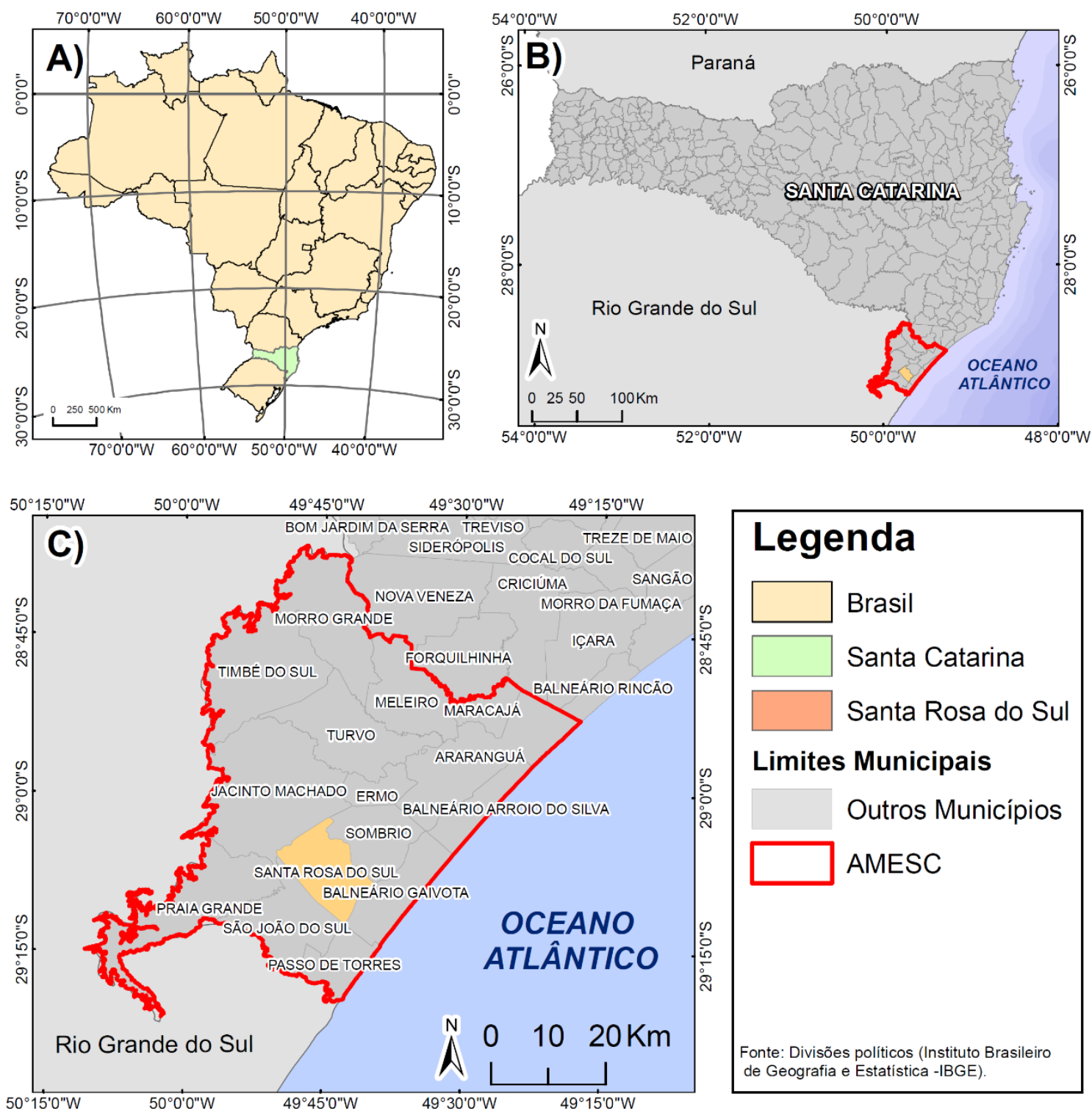

\section{Legenda}

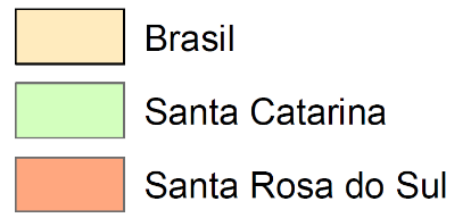

\section{Limites Municipais}

Outros Municípios

AMESC

Fonte: Divisões políticos (Instituto Brasileiro de Geografia e Estatistica -IBGE).

\section{2 ÁREA DE ESTUDO}

O município de Santa Rosa do Sul, no qual está compreendida a área de estudo encontra-se inserido no extremo sul de Santa Catarina, com latitude de $29^{\circ} 08^{\prime} 10^{\prime \prime S}$, uma longitude de $49^{\circ} 42^{\prime} 00^{\prime \prime} \mathrm{W}$ de Greenwich e numa altitude média de 7,5 metros em relação ao nível do mar, localizado a menos de $15 \mathrm{~km}$ do Oceano Atlântico e a $20 \mathrm{Km}$ dos contrafortes da Serra Geral, característica geomorfológica esta que condiciona o desenvolvimento pouco pronunciado da rede hidrográfica. Os principais cursos d'água do município são o Rio da Lage e o Canal DNOS, que cortam transversalmente o município. Além destes, cabe destaque o corpo lêntico denominada de Lagoa do Sombrio. 
O município ocupa uma área total de $151,030 \mathrm{~km}^{2}$ (IBGE, 2019). O clima é subtropical úmido (mesotérmico), com média do mês mais quente superior a $22^{\circ} \mathrm{C} \mathrm{e}$ no mês mais frio, inferior a $18^{\circ} \mathrm{C}$, sem estação seca bem delimitada.

O perfil econômico do município baseia-se essencialmente na atividade agrícola, englobando os cultivos de arroz, mandioca e banana. Dentre as atividades industriais destacam-se o setor de processamento de madeira e o de processamento de mandioca e produção de polvilho (DAMIANI, 2017).

Segundo IBGE, (2010) com mais de 1/3 da população residindo em área rural, se faz significativo o uso de fontes alternativas de captação de água (nascentes e ponteiras). Neste sentido, buscando avaliar a qualidade da água consumida pelas comunidades rurais no município, selecionaram-se duas comunidades nas quais foram avaliados um conjunto de propriedades 10 propriedades cada (Figura 3).

Segundo Damiani (2017), os agricultores acreditam que a água que consomem é de boa qualidade. A porção preponderante nunca identificou seus problemas de saúde como relacionados com o consumo de água. Os mesmos não relataram a presença de gosto, odor, cor ou manchas em roupas e louças sanitárias.

Figura 3 - Localização da área de estudo com destaque para os pontos amostrais utilizados no presente trabalho

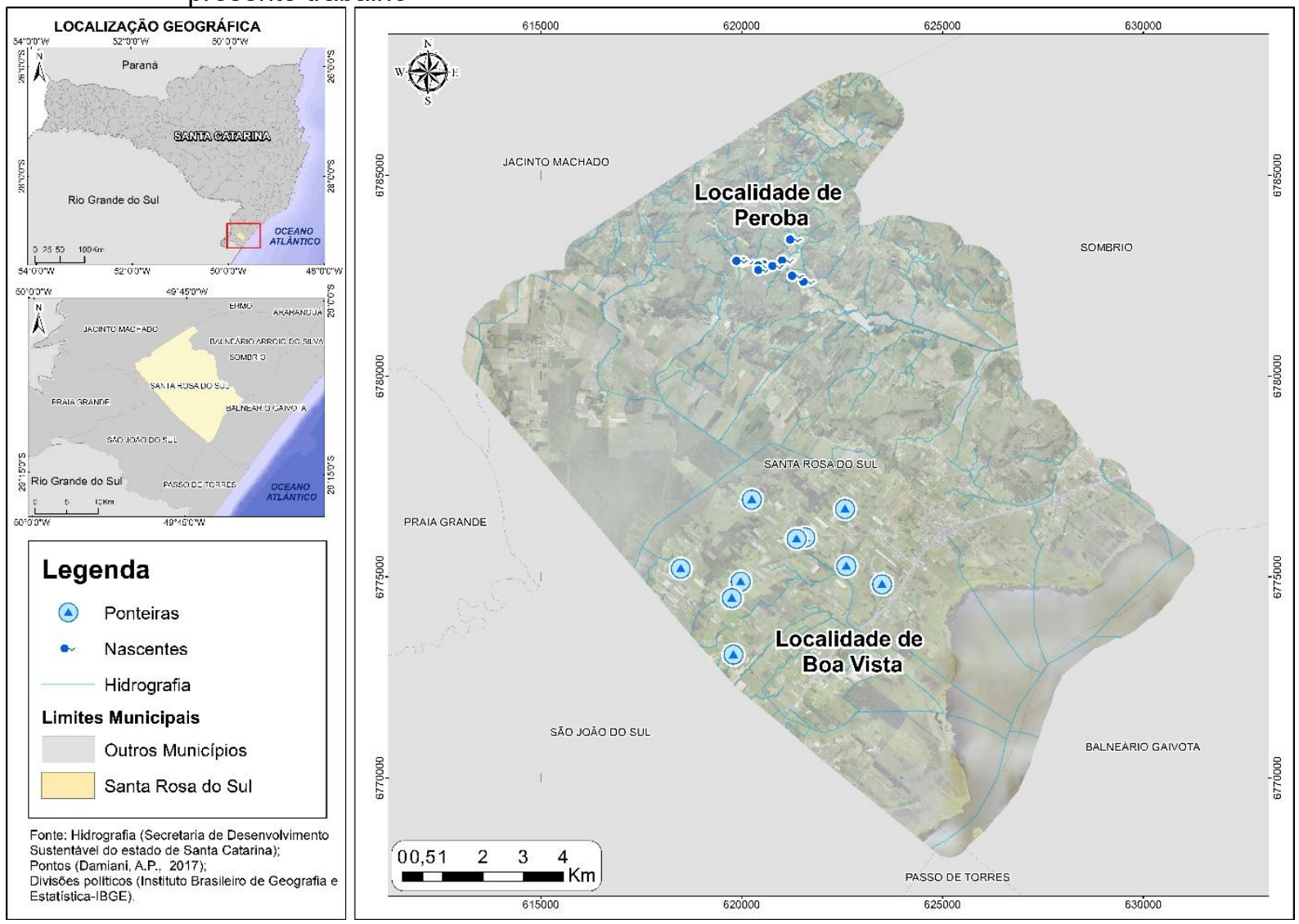




\section{CONTEXTO GEOLÓGICO E HIDROGEOLÓGICO}

A área do município que sedia o presente estudo está inserida no contexto geológico regional da interface entre a borda leste da Bacia do Paraná e a planície costeira, representada pela porção emersa da Bacia de Pelotas. Neste sentido, encontram-se representados ao longo do território do município dois contextos geológicos e hidrogeológicos distintos, Bacia do Paraná e Planície Costeira.

Baseados nesta distinção hidrogeológica, foram definidos dentro do município duas áreas prioritárias, as quais correspondem às localidades de Peroba e Boa Vista nas quais 20 pontos (10 para cada comunidade) de captação de água foram selecionados aleatoriamente e avaliadas (Figura 4). Estas foram selecionadas de forma representativa, pois perfazem os dois compartimentos geológicos existentes no município.

No contexto da Bacia Vulcano-sedimentar do Paraná foi selecionada a comunidade de Peroba (Figura 4), onde litologias siliciclásticas da Formação Botucatu e subordinadamente ígneas da Formação Serra Geral compõem o embasamento geológico (SANTA CATARINA, 2014). Neste contexto, ocorrem aquíferos porosos relacionados aos arenitos da Formação Botucatu e aquíferos fissurais relacionados às fraturas das litologias ígneas. A obtenção de água neste contexto dá se predominantemente por meio da captação de nascentes, haja vista a dificuldade e custos de se empreender perfuração nestas rochas profundamente litificadas.

Em se tratando do contexto de planície costeira, foi selecionada a comunidade de Boa Vista (Figura 4). Nesta ocorrem depósitos sedimentares inconsolidados siliciclásticos, pelíticos e eventualmente turfeiras, relacionados a processos de planície lagunar, eólicos, Colúvio-aluvionares e praiais Cenozoicos de idades Pleistocênicas e Holocênicas. Neste contexto, ocorrem aquíferos porosos relacionados aos depósitos arenosos e aquitardos ligados aos depósitos pelíticos e turfosos.

As captações de água neste contexto dão se predominantemente por meio da perfuração de poços do tipo ponteira. Este fato tem relação com a facilidade de se desenvolver perfuração hidráulica nestes sedimentos inconsolidados. 
Figura 4 - Contexto geológico das localidades e pontos amostrais utilizados no presente trabalho

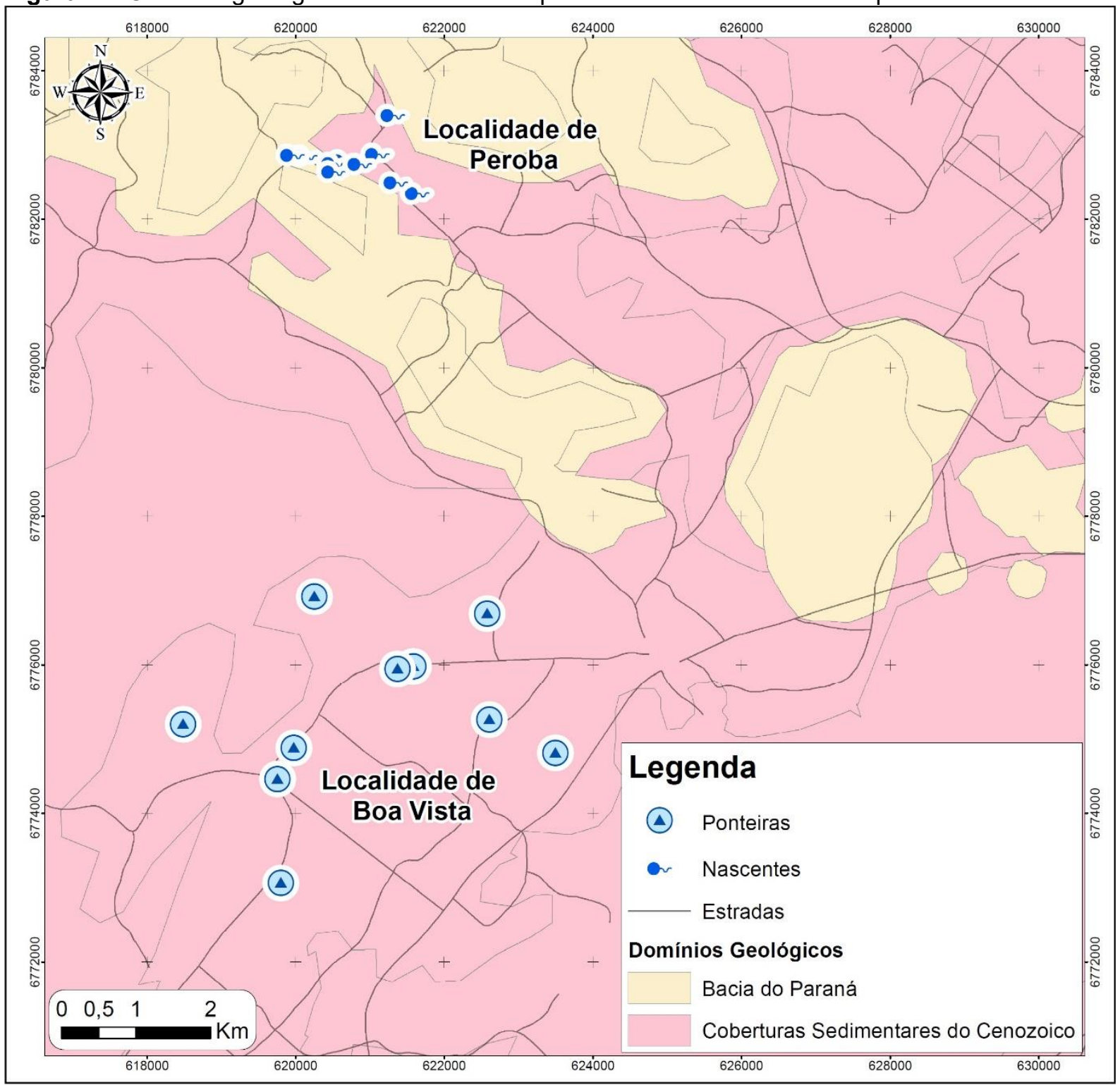

\section{METODOLOGIA}

Os pontos de captação de água em cada comunidade foram selecionados aleatoriamente dentre cada um dos respectivos contextos, de forma a se ter representatividade de ambas as características hidrogeológicas. Foram obtidas 20 amostras de água, sendo 10 amostras provenientes do contexto da bacia do Paraná, obtidas por meio da captação de nascentes, na comunidade da Peroba (Figura $5 \mathrm{~A} \mathrm{e}$ B) e 10 provenientes da área de coberturas Cenozoicas, captadas na forma de água subterrânea por meio de poços do tipo ponteira, na comunidade de Bela Vista (Figura 5 C e D). 
Figura 5 - A e B) Exemplos de pontos de captação de água em nascentes relacionados ao contexto hidrogeológico da Bacia do Paraná, C e D) exemplos de pontos de captação de água em poços tipo ponteira relacionados ao contexto hidrogeológico das Coberturas Cenozóicas
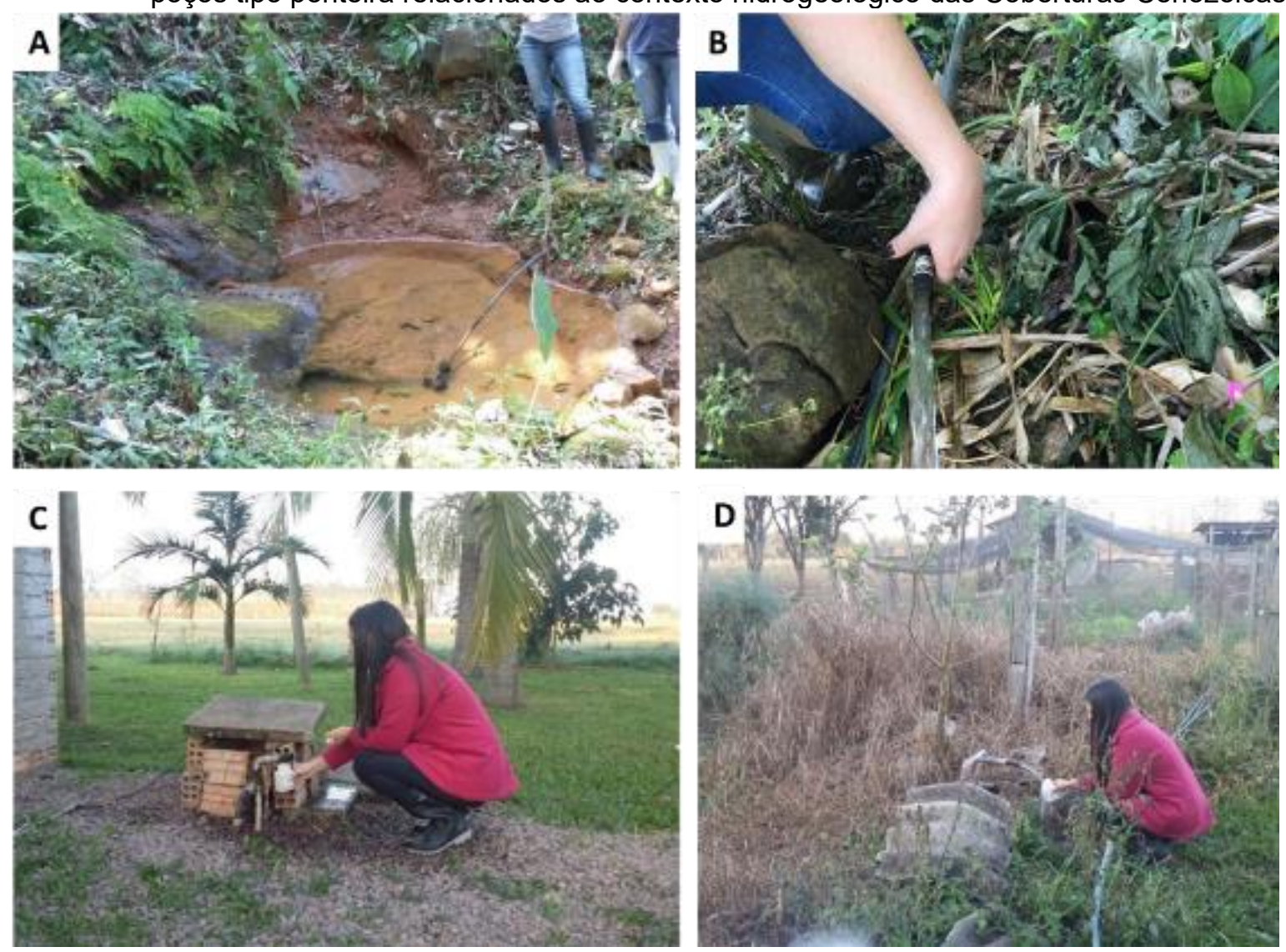

Para a coleta das amostras destinadas as análises microbiológicas, foram utilizados frascos de plástico, devidamente esterilizados. Logo após a coleta, estes foram armazenados em caixa térmica com gelo e encaminhados para análise em tempo inferior a 4 horas. Para a coleta das amostras destinadas as análises físicoquímicas, utilizaram-se garrafas pet de água mineral, devidamente desinfetadas com álcool $70 \%$ e armazenadas em refrigerador até a data da análise (Figura 6).

Os pontos de coleta de água, geralmente mangueiras ou torneiras, foram desinfetadas com algodão embebido com álcool $70 \%$, deixando-se posteriormente o sistema em água corrente por 2 minutos antes da obtenção da alíquota de água destinada às análises. As amostras oriundas de nascentes foram identificas pela letra $\mathrm{N}(\mathrm{N}-01$ a $\mathrm{N}-10)$, enquanto as oriundas de poços ponteira foram identificadas pela sigla $\mathrm{P}(\mathrm{P}-01$ a $\mathrm{P}-10)$.

Para as análises microbiológicas, seguiu-se a metodologia de padronização da técnica dos tubos múltiplos, conforme descrita pela American Public Health Association (APHA, 2012). Para determinação de pH foi utilizado aparelho da marca 
Digimed, calibrado com solução tampão de pH 7. Para determinação dos parâmetros ferro e alumínio utilizou-se o equipamento Espectrofotômetro - Digital UV-Visível, faixa 190-1100nm, com varredura, da marca Shimadzu.

Figura 6 - Frascos utilizados na coleta e acondicionamento das amostras destinadas á; A) análises microbiológicas e B) análises físico-químicas

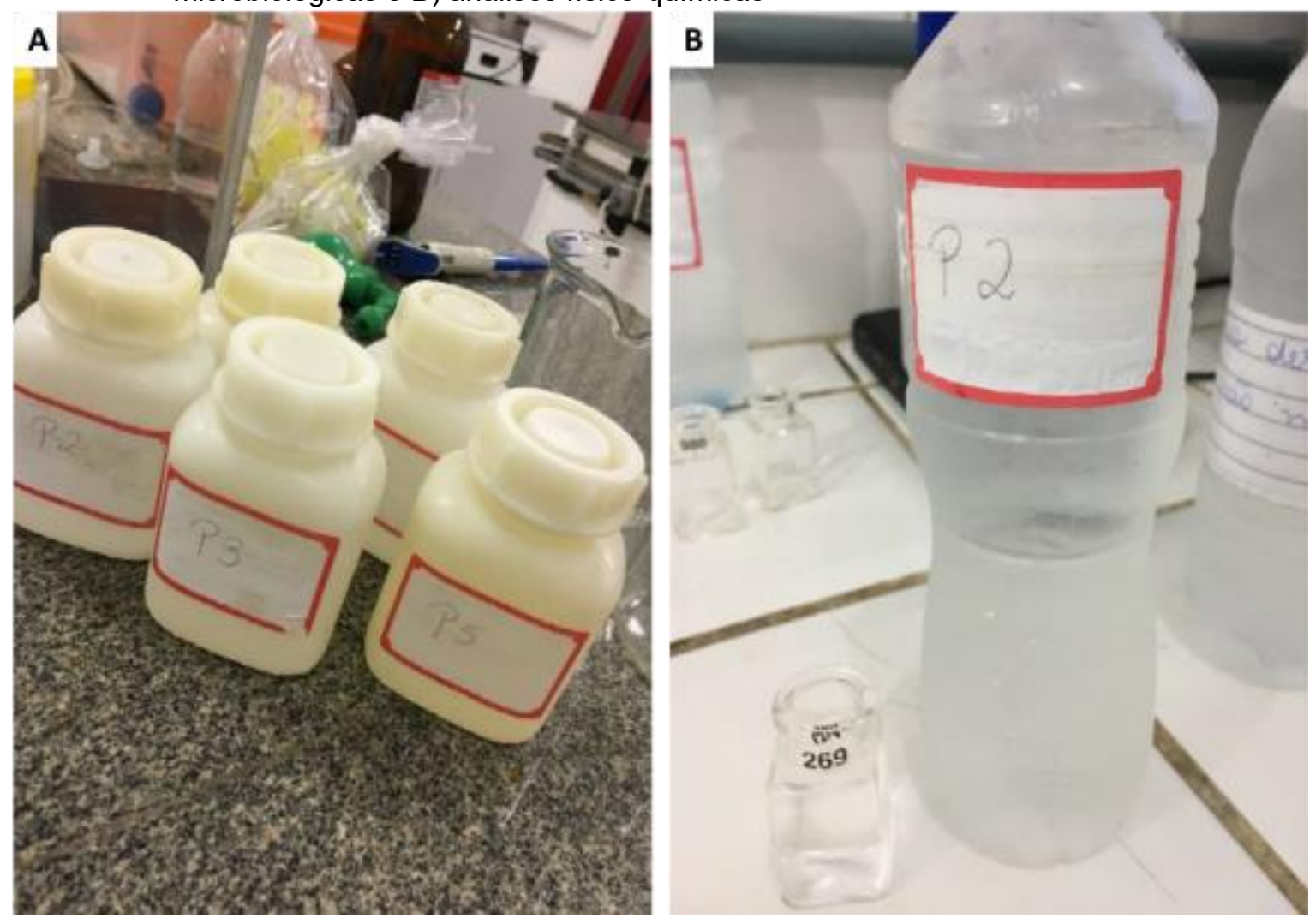

\section{RESULTADOS E DISCUSSÕES}

O parâmetro $\mathrm{pH}$ apresentou comportamento uniforme de acordo com o compartimento avaliado, contudo, uma diferença significativa entre os contextos hidrogeológicos foi observado. As águas oriundas de nascentes apresentaram um $\mathrm{pH}$ próximo da neutralidade, enquanto as amostras coletadas em poços do tipo ponteira apresentaram valores de $\mathrm{pH}$ próximo a 5 (Figura 7).

Esta diferença significativa é interpretada como correlacionável ao contexto hidrogeológico em que se encontram implantadas as ponteiras avaliadas. As Coberturas Cenozóicas encontram-se aqui representadas pelos sedimentos inconsolidados correlacionados à Planície Costeira Catarinense, com abundantes camadas pelíticas ricas em matéria orgânica, assim como esporadicamente depósitos 
de turfa. Os processos de maturação desta matéria orgânica são responsáveis pela ligeira acidificação da água observada, quando são liberados ácidos orgânicos no ambiente saturado do aquífero freático.

As concentrações de ferro (Figura 7A) indicaram que os pontos de captação em nascentes predominantemente apresentam concentrações inferiores a 0,2mg/L, encontrando-se em conformidade com os limites de potabilidade. Somente em dois pontos os resultados ultrapassam a concentração de $0,3 \mathrm{mg} / \mathrm{L}$, preconizada pela Portaria Consolidada $\mathrm{n}^{\circ} 5$, do Ministério da Saúde, que versa sobre potabilidade em seu anexo XX (BRASIL, 2017). Dois pontos apresentaram concentrações próximas a $1,0 \mathrm{mg} / \mathrm{L}$, caracterizando estes pontos como não potáveis sem tratamento.

Nos pontos de captação em poços do tipo ponteira, nenhum dos pontos avaliados apresentou concentrações que suplantassem os limites preconizados pela citada portaria consolidada. De modo geral, as amostras de nascentes apresentaram concentrações de ferro superiores ao observado nas ponteiras, este fato explica-se pelo contexto hidrogeológico ao qual cada uma dessas tipologias de captação está relacionada. As nascentes estão em contato com litologias da Bacia VulcanoSedimentar do Paraná, com destaque para os arenitos da Formação Botucatu e basaltos da Formação Serra Geral. Os processos de alteração das rochas basálticas tipicamente geram abundância de ferro solúvel nas águas, tanto que estas litologias são popularmente conhecidas como pedra ferro.

Avaliando-se as concentrações de alumínio (Figura 7B), observam-se que as nascentes, apresentam-se em conformidade com uso da água como potável $(>0,1 \mathrm{mg} / \mathrm{L})$. Em contrapartida, $50 \%$ das amostras obtidas em ponteiras apresentaram concentrações que ultrapassam o valor de $0,2 \mathrm{mg} / \mathrm{L}$, valor estabelecido como limitante pela Portaria Consolidada $\mathrm{n}^{\circ} 5$ para este parâmetro.

O comportamento das concentrações de alumínio nos poços do tipo ponteira é creditado às características inerentes ao seu ambiente hidrogeológico. $\mathrm{O} \mathrm{pH}$ ácido ocasionado pela contribuição húmica dos sedimentos carbonosos eleva a solubilidade do alumínio em meio aquoso, elevando as concentrações do metal neste compartimento analisado. 
Figura 7 - Resultados analíticos dos parâmetros físico-químicos avaliados, sendo na cor azul os resultados de águas obtidas em nascentes e em laranja águas obtidas em ponteiras; A) Ferro vs $\mathrm{pH}$ e B) Alumínio vs $\mathrm{pH}$
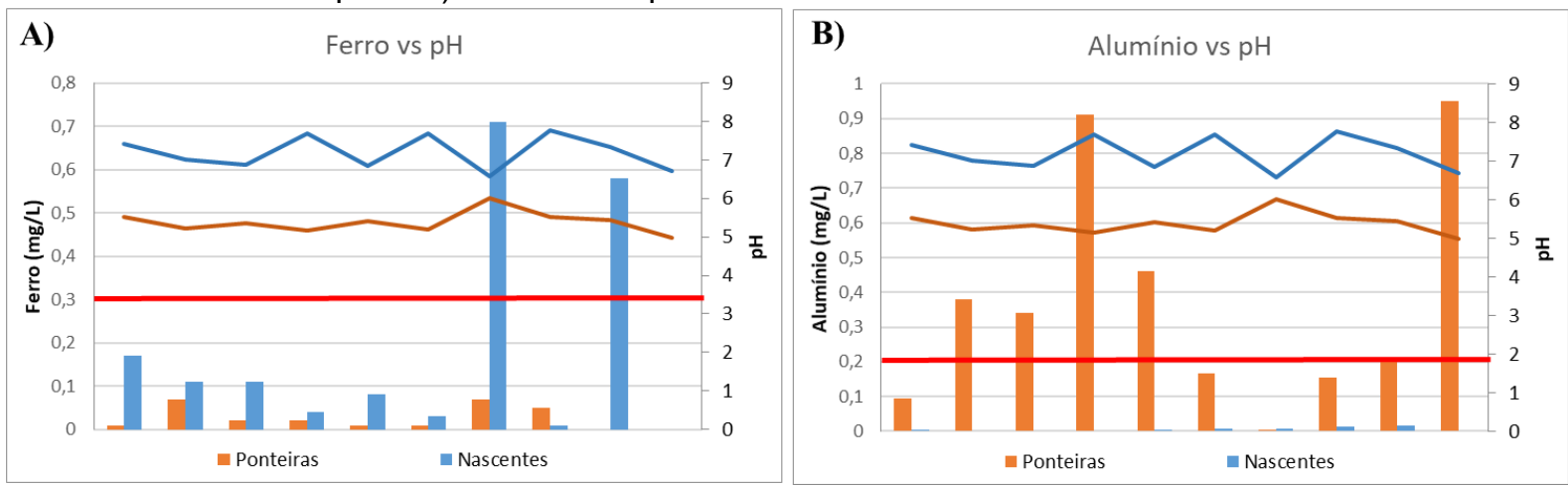

Com relação aos parâmetros microbiológicos, as amostras advindas de captações de nascentes apresentaram de forma geral contaminação por bactérias do tipo Coliformes. Esta situação não surpreendeu, uma vez que o cenário observado com nascentes desprotegidas e expostas a diversos tipos de focos de poluição, tanto como antrópicas quanto animais domésticos e silvestres prenunciava o potencial de contaminação. Os coliformes podem estar envolvidos tanto em infecções intestinais quando na participação de diversas outras patologias, uma vez que são indicadores do potencial patogênico do ambiente. As infecções causadas por estes organismos ocorrem principalmente por via oral, como a veiculação hídrica, envolvendo múltiplos modos de transmissão (TORTORA, FUNKE e CASE, 2012). A presença de coliformes termotolerantes, demonstra que ocorre poluição fecal provenientes de animais de sangue quente, incluindo o homem.

De acordo com a Portaria Consolidada $n^{0} 5$ do Ministério da Saúde (BRASIL, 2017), a água para consumo humano deve ter ausência de indicadores de contaminação fecal. Apenas uma das nascentes apresentou condições de não contaminação por parâmetros microbiológicos.

Já as amostras de água obtidas em poços do tipo ponteira apresentaram um cenário melhor em termos de potabilidade. Dentro do conjunto de amostras analisadas, somente uma delas apresentou níveis de coliformes, indicativo inequívoco de contaminação microbiológica. 
Tabela 1 - Resultados dos parâmetros microbiológicos

\begin{tabular}{|c|c|c|c|}
\hline Ponto & $\begin{array}{l}\text { Coliformes totais } \\
\text { (NMP/100mL) }\end{array}$ & $\begin{array}{l}\text { Coliformes termotolerantes } \\
\text { (NMP/100mL) }\end{array}$ & $\begin{array}{c}\text { Contagem padrão } \\
\text { (UFC/mL) }\end{array}$ \\
\hline N1 & $3,5 \times 10^{3}$ & $3,5 \times 10^{3}$ & $4,5 \times 10^{2}$ \\
\hline N2 & $>1,6 \times 104$ & $>1,6 \times 104$ & $9 \times 10^{2}$ \\
\hline N3 & $>1,6 \times 104$ & 6,8 & $2,4 \times 10^{1}$ \\
\hline N4 & $5,4 \times 10^{2}$ & $2,4 \times 10^{2}$ & $5 \times 10^{2}$ \\
\hline N5 & 6,8 & 4 & $9,3 \times 10^{2}$ \\
\hline N6 & Ausente & Ausente & $2,2 \times 10^{1}$ \\
\hline N7 & $1,6 \times 104$ & $1,1 \times 10^{3}$ & $1,3 \times 10^{3}$ \\
\hline N8 & $3,5 \times 10^{2}$ & $3,5 \times 10^{2}$ & $1,1 \times 10^{2}$ \\
\hline N9 & $1,6 \times 104$ & $3,5 \times 10^{2}$ & $1,6 \times 10^{3}$ \\
\hline N1 & $3,5 \times 10^{2}$ & $1,1 \times 10^{2}$ & $1,5 \times 10^{3}$ \\
\hline P1 & $<2,0^{*}$ & $<2,0$ & $1,7 \times 10^{1}$ \\
\hline P2 & $<2,0$ & $<2,0$ & Ausente \\
\hline P3 & $<2,0$ & $<2,0$ & $1,0 \times 10^{2}$ \\
\hline P4 & $<2,0$ & $<2,0$ & Ausente \\
\hline P5 & $<2,0$ & $<2,0$ & $1,3 \times 10^{2}$ \\
\hline P6 & $<2,0$ & $<2,0$ & Ausente \\
\hline P7 & $3,5 \times 10^{3}$ & $2,4 \times 10^{3}$ & $2,8 \times 10^{3}$ \\
\hline P8 & $<2,0$ & $<2,0$ & Ausente \\
\hline P9 & $<2,0$ & $<2,0$ & Ausente \\
\hline P10 & $<2,0$ & $<2,0$ & $1,1 \times 10^{2}$ \\
\hline
\end{tabular}

Conforme alertado por Zulpo (2006), os organismos do tipo Coliformes termotolerantes, não se reproduzem fora de seu habitat (intestino de animais de sangue quente) e apresentam uma taxa de sobrevida de algumas horas. Neste sentido, a espessa camada de sedimentos inconsolidados pelos quais um eventual contaminante superficial tem que percolar para atingir o ponto de captação da ponteira, acaba por atuar como filtro, depurando a contaminação microbiológica.

Sampaio et al., (2019), avaliando a água de fontes de abastecimento domiciliar e da agroindústria alimentar do Planalto Catarinense - Santa Catarina, chegou a resultados similares ao presente trabalho, com $80 \%$ dos pontos avaliados indicando presença de coliformes termotolerantes.

Já Amaral et al. (2003), avaliando fontes de água de zonas rurais no nordeste do Estado de São Paulo, demonstrou que 90\% das amostras de fontes apresentaram inaptidão para consumo humano, sendo que $80 \%$ destas fontes eram de profundidade inferior a $20 \mathrm{~m}$. O mesmo autor relata a observância de variabilidade nos valores médios de coliformes obtidas na estação seca e na estação úmida, sendo na estação 
úmida observados os maiores valores. O autor relaciona tais variações a susceptibilidade á contaminação proporcionada pela percolação de contaminantes oriundos da superfície.

\section{CONSIDERAÇÕES FINAIS}

A análise e compreensão dos contextos hidrogeológicos e sanitários da porção territorial do município de Santa Rosa do Sul, aliados as observações em campo e os resultados do presente trabalho permitiram concluir que a situação da qualidade da água consumida nas áreas rurais é imprópria.

Mesmo para o reduzido número de parâmetros avaliados no presente estudo, em $90 \%$ das amostras obtidas em nascentes não apresentaram condições de potabilidade, sendo que, para algumas delas, mais de um dos parâmetros analisados encontravam-se em inconformidade sanitária. O mais preocupante é a contaminação microbiológica identificada em $90 \%$ das amostras.

A situação nas captações do tipo ponteira é um pouco melhor, com $30 \%$ das amostras em condição de potabilidade. O maior problema neste contexto está associado à presença de alumínio com concentração acima do limite estabelecido para potabilidade. O incremento de alumínio está associado às características geogênicas. Apenas uma amostra apresentou contaminação microbiológica, sendo esta de forma bastante acentuada.

Na área de estudo, dois contextos hidrogeológicos são discerníveis e imprimem características diferentes à água. No domínio da Bacia do Paraná, predominam litologias sedimentares e vulcânicas, onde a captação da água é realizada em exsudações superficiais, por meio da captação de nascentes. Nestes pontos, a situação mais crítica refere-se à contaminação microbiológica dada pela forma de captação e proximidade com fontes de contaminação.

Já no contexto das coberturas cenozoicas de planície costeira, as derivações de água são realizadas na forma de poços do tipo ponteira, em sedimentos inconsolidados siliciclásticos e pelíticos, esporadicamente ricos em matéria orgânica. Esta composição influencia a característica da água, a qual tem incremento de alumínio, relacionado provavelmente a solubilidade deste proporcionada pela característica mais ácida do meio $(\mathrm{pH} \sim 5)$. 
De modo geral, em consonância outros trabalhos, o presente estudo alerta para a condição da qualidade de abastecimento de água para a população rural. Conforme visto, os dados regionais apontam para um cenário negativo em termos de riscos à saúde pública, corroborado pelos dados avaliados e discutidos no presente trabalho. Cenário este que pode resultar em elevados índices de transmissividade de doenças infeciosas.

\section{REFERÊNCIAS}

APHA - American Public Health Association. Standard methods for the examination of water and wastewater: estimation of bacterial density. multiple-tube fermentation technique for members of the coliform group. American Water Works Association, Water Environment Federation. 22th ed Washington, D.C., 2012.

AMARAL, L.A. do; FILHO, A.N.; ROSSI, O.D.; ALVES FERREIRA, F.L.; SOARES BARROS, L.S. Água de consumo humano como fator de risco à saúde em propriedades rurais.

Revista de Saúde Publica, v. 37, n. 4, p. 510-514, 2003. https://doi.org/10.1590/S0034$\underline{89102003000400017}$

BERNARDI, C.C. Reuso de água para irrigação. Monografia MBA. ISAEFGV/ECOBUSINESS. Brasília, DF, 2003. 52p.

BRASIL. Vigilância e controle da qualidade da água para consumo humano. Ministério da Saúde, Secretaria de Vigilância em Saúde. - Brasília, 2006. 212 p. Disponível em: http://bvsms.saude.gov.br/bvs/publicacoes/vigilancia controle qualidade agua.pdf. Acesso em: 17 jan. 2020.

BRASIL. Portaria n. 5, de 28 de setembro de 2017. Consolidação das normas sobre as ações e os serviços de saúde do Sistema Único de Saúde. Disponível em: http://portalarquivos2.saude.gov.br/images/pdf/2018/marco/29/PRC-5-Portaria-deConsolidada nำ de 28 de Setembro de 2017.pdf, 2017. Acesso em: 30 ago. 2019.

DAMIANI, A. P. M. Qualidade da água em propriedades rurais do município de Santa Rosa do Sul, Santa Catarina. 45 f. TCC (Graduação) - Curso de Ciências Biológicas, Universidade do Extremo Sul Catarinense - UNESC, Criciúma, 2017.

FEITOSA, F. A. C.; FILHO, J. M.; FEITOSA, E. C.; \& DEMÉTRIO, J. G. A. Hidrogeologia: conceitos e aplicações. Rio de Janeiro, CPRM:LABHID, 2008. 812p

IBGE. Instituto Brasileiro de Geografia e Estatística. Censo Demográfico 2010. Rio de Janeiro, 2010. Disponível em: http://censo2010.ibge.gov.br. Acesso em: 02 set. 2019.

IBGE. Instituto Brasileiro de Geografia E Estatística. IBGE Cidades. 2019. Disponível em: http://cidades.ibge.gov.br/painel/painel.php?codmun=421565. Acesso em: 10 ago. 2019.

SAMPAIO, C. A. de P., IDE, G. M., BATALHA, C. P., PEREIRA, L. C., BUENO, L. F. Análise técnica de água de fontes rurais. Engenharia Sanitaria e Ambiental, v. 24, n. 2, p. 213217, 2019. https://doi.org/10.1590/s1413-41522019116954

SANTA CATARINA. Atlas geográfico de Santa Catarina diversidade da natureza: Fascículo 2. Florianópolis: UDESC, 2014. 188 p. 
SANTA CATARINA. Vigilância Sanitária, Secretaria de estado da Saúde, Estado de Santa Catarina. Disponível em: http://www.vigilanciasanitaria.sc.gov.br/ Acesso em: 30 ago. 2019.

TORTORA, G.J; FUNKE, B.R.; CASE, C.L. Microbiologia. 10. ed. Porto Alegre: Artmed, 2012. 934p.

UNESCO. United Nations World Water Development Report 2019: Leaving No One Behind .France, 2019. Disponível em: https://unesdoc.unesco.org/ark:/48223/pf0000367306. Acesso em: 11 jul. 2019.

WHO. World health statistics. N. I: World Health Organization, 2011. 171 p. Disponível em: https://www.who.int/gho/publications/world health statistics/EN WHS2011 Full.pdf. Acesso em: 30 ago. 2019.

ZULPO, D. L.; PERETTI, J.; MORTEAN O. L.; GARCIA, J. L. Avaliação microbiológica da água consumida nos bebedouros da Universidade Estadual do Centro-Oeste, Guarapuava, Paraná, Brasil. Seminário: Ciências Agrárias, p. 107-110, jan./mar. 2006.

https://doi.org/10.5433/1679-0359.2006v27n1p107 